\title{
How Chinese Culture Goes to the World through Literary Translation
}

\author{
Yuanzhen Peng \\ School of Foreign Languages, North China Electric Power University, Baoding, China
}

\begin{abstract}
The fact that Mo Yan won the Nobel Prize for Literature is a landmark event of the evident increase of Chinese culture's international influence. In the light of literary translation, culture occupies an important position. Thus, the way of handling cultural difference is of great importance in improving translations' quality and promoting cultural exchange among countries. However, the shortage of qualified literary translators makes literary translation a worse situation. This dissertation will mainly discuss about the cultural transmission through literary translation and the cultivation of talented translators. The ultimate goal of this paper is to expand Chinese culture's international influence through improving literary translation.
\end{abstract}

Index Terms-literary translation, cultural difference, literary translators

\section{INTROdUCtion: The CURRENT CONDITION OF CHINESE LitERARY TRANSLATION}

With the integration of global economy, politics and science technology, the tendency of multi-cultural coexistence is underway. Culture is becoming greatly important in the exchange among countries. As a branch of translation, literature translation is kind of cross-cultural language transforming art. In the sense of culture, literature translation is to have the content, the style, the spirit of a book under a certain cultural context reappear in another cultural context. Concerning the cross-cultural nature of literature translation, the translator is required to transcend cultural differences and take up literature translation in a creative way so that the aim of literature communication and cultural exchange can be met.

Nowadays, following the departure of such literature translating masters as Fengzhi, Xiaoqian, Luxun and Feng Yidai, the literature translating sector soon entered a declining period and falls into an embarrassing situation. And we have to admit that the quality of Chinese literature translation works is not very satisfactory and that there is an increasing lack of excellent translators. Chinese literature translation is regarded as one way of pushing Chinese culture towards the world. This paper will reflect on some key and practical issues in connection to helping Chinese culture through literature translation go to the world, and propose relevant suggestions.

\section{The Blocking Forces That Stand in the Way of Chinese Culture in Literature Translation Going to the WORLD}

The blocking forces standing in the way of Chinese culture through literature translation going to the world can be divided into two categories. One is the difficulty in translating Chinese works, which is the cultural translation and reproduction. The other is the lack of translators, who are devoted to the field of Chinese literature translation.

\section{A. Cultural Differences between the East and the West}

1. Different Historical Backgrounds

Under different historical backdrops, different nations have accumulated massive vocabularies featuring rich implication, unique images and culture. In translating those words, we can not comprehend them literally, otherwise, the translated text may appear confusing and elusive to readers. What's more, It can often been seen that different culture has a different understanding of the same thing or the same concept. For instance, in Big Breasts and Wide Hips (Mo, 1996), there is an excerpt: 她阴沉沉的说:“如果我没记错的话,你戴的,”她用手做了一个摘帽子的姿势, “不是“手 提帽”，你是极右派，是属于永久性、永远找不掉帽子的右派，对不对?” and the translation is “Unless I'm mistaken," she said darkly, "you have been capped." She reached up as if taking a hat off her head. "Not a cap you can remove at will. No, you're an ultra-rightist and that will be with you forever, a rightist who will always wear the cap. Am I right". "Cap" is a feature word used in the period of Chinese Cultural Revolution. It refers to "setting somebody up". In the course of translation, the translator only presents the image of the character without telling readers the loaded culture. Readers may get confused in doing reading and can hardly figure out the cultural implication. Thus, I think a foot note is needed here-"cap" is a special word used during The Cultural Revolution, Which means to stick unwarranted labels on someone. This, to some degree, reveals the cultural meaning of "hat" in accordance with the context.

2. Different Ways of Thinking

Ways of thinking is bound to the origin of a nation's rich culture, which reflects the language psychological tendency a nation of a certain language formed in the course of history. The western people are used to logical and abstract 
thinking, while Chinese are inclined to visual thinking. Both sides hold lots of great differences in religious and historical tradition, philosophy, language and culture. Compared with the impact of relatively abstract thinking, material factors like geographical conditions have more concrete and trivial impacts on translation appreciation. Take Life and Death are Wearing Me Out by Mo Yan as an example.

“而黄合作又对他频频进攻，于是他跟她又有了云雨之情。”(Mo, 2006, p. 252)

"When Huang Hezuo made her move, and they sported among the clouds and rain." (Goldblatt, 2008, p. 278)

The Chinese people are not as bold as many Westerners when talking about sex, so they usually use euphemism to imply the things related to sex. “云雨” is a more literary speaking of sexual intercourse, an euphemism that derives from ancient Chinese poetry. Convinced that the target readers could understand it within the context, Goldblatt renders the euphemism into "among the clouds and rain" in the foreignizing method. Therefore, the Chinese cultural metaphor is well preserved, and at the same time, the target readers could experience the exotism and uniqueness of the Chinese culture.

3. Different Habits and Customs

Different nations have different living customs. For instance:

附骥尾莫言巴结常团长 (Mo, 2006, p.305)

A Fawning Mo Yan Rides on Commander Chang's Coattails (Goldblatt, 2008, p.327)

The idiom “附翼尾” comes from Records of the Grand Historian (司马迁《史记》). It literally means to “adhere to a splendid steed's tail" and its figurative meaning is "to come to fame by relying on an influence or put oneself under the patronage of a bigwig", used often in a self-effacing speaking. The word "coattails" literally means the skirts of a dress coat, or frock coat and its figurative meaning is the influence of a popular movement or person. The English phrase "to ride on one's coattails" means to get promoted politically by relying on another person's fame and prestige, which is similar to “附翼尾”, though their derivations are different and have different cultural images. In this sense, Goldblatt's translation is as visual as the original.

\section{B. A Lack of Excellent Groups of People Engaged in Literary Translation}

Literature translation covers a wide range of subjects. Jeremy Munday defines translation in Introducing Translation Studies as a new subject in close connection to translation theories and behaviors. This definition obviously reveals the cross-subject quality of translation, which goes for literature translation. Therefore, a solid foreign language basis does not equal excellent translation competence which also needs wide general knowledge, good language expressive skills, long-term practice and accumulation.

The main reason which results in lacking translators is that literature translation demands high level of literature of translators. Literary works present a whole society, a nation and people's life. Before translating a book, a translator should have a good understanding of the whole ideological basis and cultural tradition. As a literary translator, he or she should have a comprehensive storage of mother language, Chinese Classics, wide scope of knowledge, rich life experience and cultural accumulation.

However, the common problem that most translators face is a weak Chinese Classics basis and narrow scope of general knowledge. Recently an increasing number of Doctoral supervisors of foreign language call that students in foreign language majors must strengthen the study of Chinese Classics and general knowledge, otherwise, they will lack confidence whether in their further study or at work. What's more, the multiplicity and cross-cultural quality of literature translation show us that the only foreign language basis can not afford to help literary translators make great accomplishments in the field of literary translation.

Generally speaking, the reserve literary translators are mainly from foreign language majors. Nowadays, despite the fact that the environment for foreign language study has improved a lot, many students learn it with a strong utility. In this connection, He Gangqiang, Doctoral supervisor of Fudan University, pointed out that many students regard English as a means of seeking a satisfactory job after graduation.

In addition, the major difference between literary translation and other types of translation is not only a simple literary translation, but rather a hard process of reproduction. For example, during the time when Mr Luo Xinzhang translated the Red and the Black, he almost went on his translation word for word and translated just 300 words a day. This explains why many of the older generation of translators are writers, literary critics and masters of general knowledge. All in all, literary translation is a cause which needs many translators to devote themselves to.

\section{Ways to Solve Those Problems}

\section{A. Ways to Address Cultural Differences in the Course Of Literary Translation}

\section{A Good Analysis of Literary Genre}

Translation practice is in close connection with the style of translated works. Translated works of different styles has distinctive language characteristics. Only when translators have a good grasp of the language characteristics of both source language and target language and can apply the two languages freely can their translations truly reflect the style of source language.

The difference between language styles means different culture involved. For example, in terms of scientific articles, 
a relatively small amount of culture is loaded. In doing such translation, an exact information rendering of source language into target language is much more important than the culture rendering of two languages. By contrast, as regards literary works like novels, poems and essays, culture is what should be taken seriously in translation. From readers' perspective, the translation lacking culture is one having no soul. Thus, a qualified translator should fully take into account the way how to handle the cultural difference among works of different styles in literary translation practice.

Of all literary works, poem carries the most cultural elements in light of forms and contents. For instance, the English sonnet and the Chinese poems with seven patterns respectively present deep cultural feature. Many translation techniques such as supplementation, annotation, back-translation and replacement, all can be used to deal with cultural difference so that the readers of target language can fully comprehend the cultural style of source language. It is known that Chinese stresses parataxis while English emphasizes hypotaxis. Therefore, in Chinese-English translation, we can generate coherent context and resolve cultural difference through adding the subject, the object or the linking words. Take On Hearing the News that My Friend Bai Juyi Is Relegated to Jiujiang(闻乐天授江州司马) by Yuan Zhen for example, the line “暗风吹雨入寒窗” is translated into “Into my window a dark wind with a cold rain blows strong” by Guo Zhuzhang. This translation matches the characteristics of English and illustrates the culture involved in the poem as well.

Before starting translation, it is a crucial step to go on a thorough analysis of the literary genre and language characteristics. Translators should adopt supplementation, annotation and replacement to reduce the cultural difference between Chinese and English.

2. The Application of Dynamic Equivalence

In order to set a standard for the transformation of source language and target language and reduce cultural difference, Eugene $\cdot \mathrm{A} \cdot \mathrm{Nida}$, from linguistic perspective, has put forward the famous translation theory of Dynamic Equivalence or Functional Equivalence. In this theory, he pointed out that translation is to use the most appropriate, natural and equivalent language to reproduce the information of source language from meaning to literary genre(Guo, 2000, p.65). The information translation should convey includes both superficial word information and deep cultural information. Dynamic equivalence covers four aspects: word equivalence, syntactical equivalence, textual equivalence and stylistic equivalence. With a view to the four aspects, Nida supposed that "meaning is the most important, and the style secondary"(Guo, 2000, p.67). Style is very likely to cover up the source language's culture and block cultural exchange. Thus, in literary translation, based on the theory by Nida, the translator should make the culture of source language exactly reappear in the target language.

To recreate the culture of source language and eliminate cultural difference, the translator can follow the 3 steps. Firstly, efforts should be made to achieve the translation in accordance with the original meaning and reflecting its culture. However, two kinds of culture have something in common but can not be exactly the same. Hence, it is impossible to completely reproduce the original culture and the translator can only recreate it the best they can. Secondly, if meaning and culture can not be preserved at the same time, the translator can only desert stylistic equivalence and keep the meaning and culture of the original. For example, “太岁头上动土” is translated into “How dare they touch a single hair on the head of the mighty Jupiter!” (Goldblatt, 2000, p.116). “太岁头上动土” means, in the Chinese culture, "to provoke a person far superior in power or strength, or to scratch Buddha's head". This expression appears in Mo Yan's novel Guo and Goldblatt adopts the domestication strategy to render it into "mighty Jupiter" in Roman Methology so that the target readers could get the same meaning as the source readers do. In Life and Death Are Wearing Me Out, Goldblatt renders “太岁” into "Wandering God” on all occasions, which creativelyreproduces the people's mystification of “太岁” that the author expects to convey to his readers in the original Thirdly, if the second step does not work, another translation technique called "re-creation" can be used to resolve cultural difference. Re-creation is meant to transform the deep structure of source language into the surface structure of target language (Guo, 2000, p.67), namely, use the target language to illustrate the culture of literary works. For example, According to Nida's theory, the dealing of cultural difference is related to reproducing source language from meaning to literary style. Only when the style and spirit can be grasped in the target language can a translation be called an excellent one.

3. The Application of Domestication and Alienation

In light of culture, there are generally two translation strategies of domestication and foreignization. Foreignization reflects the culture of source language. Lawrence Venuti, an advocate of foreignization, advanced the concept of "resistancy" translation, that is to say, translations should keep source language's characteristics in style and form while overlooking whether readers of target language can understand the cultural image of source language. For translators in favor of alienation, translation promotes cultural exchange and has readers understand and accept other kinds of culture. Thus, translators should transplant source language's culture into target language so as to allow readers to directly appreciate the foreign culture. For example:

“站住！”他愤怒地一拍桌子，烟缸里烟灰被震飞起来，他说，“你是个彻头彻尾的混蛋！兔子还不吃窝边草 呢，何况也不是什么好草! ”(Mo, 2006, p.456)

"Stay where you are!" he shouted angrily, slamming his fist on the desk and sending the ashes in his ashtray flying. 
"You're a bastard, through and through. A rabbit doesn't eat the grass around its burrow, and in this case, it's not even very good grass." (Goldblatt, 2008, p.457)

Although there exists an English proverb similar to “兔子不吃窝边草” (A villain doesn’t harm his neighbors.) in meaning, Goldblatt still keeps his translation (A rabbit doesn't eat the grass around its burrow.) faithful to the original both in form and in content so that the vivid Chinese idiom could be perceived and understood by the target readers.

On contrary to alienation, adaptation reflects the culture of target language. Nida, the advocate of this theory, thinks translation should be functionally equivalent and that not only expression ways but also culture should follow target language's standard. For people who are for this idea, the duty of translation is to remove language and cultural barriers and make readers accept translations with ease. For instance:

你的角上挂着两只破鞋, 这是孙家的那个善于侍弄汽灯的小子胡乱挂上的, 只是为了丑化你,并不象征着你一 头牛也搞破鞋。(Mo, 2006, p.145)

A pair of tattered shoes had been hooked on your horns. That was the brainchild of the Sun brother who was such an expert in the use of gas lamps. He meant only to make you look bad, not imply that you dallied with loose females, as such things symbolize. (Goldblatt, 2008, p.173)

“破鞋” is a heavily culture-loaded expression with "tattered shoe” as its literal meaning. According to Wikipedia, “tattered shoe" is now an antonomasia or a metaphor and often used on the occasion of cursing a loose woman. “搞破 鞋” in Chinese means that a man and a woman have the improper sexual relations. Goldblatt's rendering "dallied with loose females" couldn't convey the exact meaning of the original because "dally" only means "to play amorously or to flirt". Therefore, "had sexual behavior with loose females" might be a better translation.

Though foreignization is diametrically opposite to domestication, nevertheless, they are not conflictory. Translators can adopt the two methods to tackle cultural difference for different outcomes according to specific conditions.

4. The Application of Creative Treason

In doing literary translation, translators often get into a dilemma of translating the works according to source language's rules or target language's. However, translations are not only the reproduction of original works but rather a re-creation of them. Robert Escarpit, a French literary sociologist, say that translation is just a sort of creative treason. Rightly owing to its existence and use, many translations are more excellent than original works come into being. For example, the poet Whitman assumed that the German version of Leaves of Grass by Freiligrath is much better than his own original. Creative treason is widely applied in literary translation for two purposes. One is to facilitate readers' cultural thinking and habits and make it easier for them to accept it. For instance, Goldblatt explained that since "Shengsi pilao" is from the Buddha's saying, the Chinese people are aware of its source, but the Americans lack such a religious background. He must find something interesting, and then he came up with the sentence "Life and Death Are Wearing Me Out". By lengthening the short four Chinese characters deliberately, Goldblatt presents the target readers an interesting and easily followed novel title with a distinctive embodiment on the plots of the stories.

The other is to introduce source language and its culture to readers of target language in a forcible way. Take the example for the famous translation by Xu Yuanchong, who rendered the palindrome sentence "Able was I ere saw Elba!” into “不到俄岛我不倒” (Xu, 1984, p. 2). Mr. Xu creatively translated the original sentence into rhythmic Chinese one with the similar forms and sounds between “到” and “倒”, “我” and “俄”. Although the rendition is not a palindrome like the original, Mr. Xu creatively reproduces the rhetorical beauty apart from fidelity to the original sentence in content.

From the perspective of literary translation means, creative treason is a crucial approach. It requires translators to add their subjective creation on the basis of correct understanding of original works and make translations more appealing. Apart from this, translations should be loyal to the translated works' gist and decrease the effect of cultural difference. To conclude, only the proper use of creative treason can effectively deal with cultural difference.

\section{B. Literary Translators'Improvement in Bilingual Competence}

Translation is the exchange and the transformation of two countries' culture. To get familiar with those cultures for translators is much more important than mastering the two languages. Nowadays, translation teaching of English major should give more weight to guiding students to know the cultural background of their mother country and foreign countries when focusing on the mastery of knowledge and language techniques. To put it in detail, curriculum should be reformed and so does translation teaching mode.

Translators' study and efforts are essential to their progress and accomplishment. The growth of translation abilities is a long-term course of practice and constant accumulation. Superb translation knowledge and skills are the goal of translators' life-long hard work. To be an excellent translator, first of all, you need to have a good mastery of mother tongue. Besides, a wide scope of knowledge and consistent learning from others and mistakes are also necessary. Only by doing so can a translator make great achievement and become qualified keeping pace with times.

What's more, young translators' literature cultivation needs improving. Huang Yuanshen said that looking at current situation, there is a noticeable problem that young translators can not deeply understand the original works and express them correctly in words. He also added for literature translators, a deep perception of works is the crucial first step of translation. Literature translation demands translators of complete focus. The wrong mentality of translating for the sake of translation is the taboo of the cause. And the good literature cultivation is the foundation of good literature 
translation.

\section{CONCLUSION}

Literary translation is a rather complicated process and it has two inseparable characteristics_— to be faithful and to be creative. What we have concluded from above is that culture is an extremely important factor in literary translation. How to handle cultural differences between source language and target language exerts direct influence on the quality and effect of translations. Besides solid language foundation, translators should also equip themselves with knowledge of bilingual cultural backgrounds and cultural awareness. With a thorough knowledge of cultural differences and proper handling of them, translators can present vivid translations to readers and contribute to cultural transmission.

What's more, our traditional culture can be constantly presented to overseas countries and more people will be lured to learn about the essence of Chinese culture. As an increasing number of literary works are translated and introduced to other parts of the world, chances of promoting cultural exchange and expanding our international influence will be growing.

\section{REFERENCES}

[1] Bassnett, Susan and André Lefevere. (eds.)(1990). Translation, History and Culture. London and New York: Printer.

[2] Chen, Xiaowei. (2010). The Rhetoric of Venuti's Conception of Foreignizing Translation. Chinese Translators Journal, 4, 5-10.

[3] Cheng, Zhaowei. (2007). An Introduction to Literary Translation. Beijing: National Defense Industry Publishing House.

[4] Dong, Ming. (2003). Creative Treason in Literary Translation. Foreign Languages and Foreign Languages Teaching, 8, 46-49.

[5] Du, Zhengming. (2000). Translation and Writing: a Study on One Hundred Year's Literary Translation. Chinese Translators Journal, 6, 47-48.

[6] Gao, Fang \& Xu, Jun. (2010). Current Situation, Problems and Suggestions - Thinking on How Chinese Literature Goes to the World. Chinese Translators Journal, 6, 5-9.

[7] Goldblatt, Howard. (trans.) (2008). Life and Death Are Wearing Me Out. New York: Arcade Publishing Inc.

[8] Goldblatt, Howard. (2009). "Mo Yan's Novels Are Wearing Me Out: Nominating Statement for the 2009 Newman Prize". World Literature Today. 2009, July- August, 28-29.

[9] Guo, Jianzhong. (2010). Translation: Theory, Practice and Teaching - A Selection of Guo Jianzhong's Papers on Literary Research. Hangzhou: Zhejiang University Publishing House.

[10] Gutt, Ersnst-August. (1992). Translation and Relevance: Cognition and Context. Oxford: Basil Blackwell Inc.

[11] Hu, Anjiang. (2010). The Translator Model of Chinese Literature Going Abroad and Studies on Translation Strategies - Take the American Sinologist Howard Goldblatt. Chinese Translators Journal, 6, 10-15.

[12] $\mathrm{Hu}, \mathrm{Mu}$. (2011). Translation Research: Return to Reality - Rethinking on Cultural Turn. Chinese Translators Journal, 5, 5-10.

[13] Huang, Youyi. (2010). Sinologists and Chinese Literary Translation - A Bridge between Chinese and Foreign Cultures. Chinese Translators Journal, 6, 16-17.

[14] Liu Jun. (2008). "Howard Goldblatt: Faithful to the Original”. China Daily, 03-12, 18.

[15] Mo, Yan. (1996). Big Breasts and Wide Hips. Beijing: Writers Publishing House.

[16] Mo, Yan. (2006). Life and Death are Wearing me Out. Beijing: Writers Publishing House.

[17] Munday, Jeremy. (2001). Introducing Translation Studies: Theories and Application. New York: Routeledge.

[18] Nida. A. Eugene. (2004). Toward a Science of Translating. Shanghai: Shanghai Foreign Language Education Press.

[19] Venuti, Lawrence. (2006). The Translator's Invisibility: A History of Translation. Shanghai: Shanghai Foreign Language Education Press.

[20] Wilss, Wolfram. (2001). The Science of Translation. Shanghai: Shanghai Foreign Language Education Press.

[21] Xu, Yuanchong. (1984). The Art of Translation. Beijing: China Translation \& Publishing Corporation.

Yuanzhen Peng was born in Jiangxi, China in 1979. She received her M.A. degree in English Language and Literature at Peking University, China in 2004.

She is currently a lecturer in the School of Foreign Languages, North China Electric Power University, Baoding, China. Her research interests include literature, translation studies and linguistics. 